\title{
47 EFFECTS OF ISOKINETIC RESISTANCE TRAINING ON FUNCTIONAL ABILITIES OF GRADE III ANTERIOR CRUCIATE LIGAMENT INJURY PATIENTS
}

Zulezwan A Malik, ${ }^{1}$ Chen Chee Keong, ${ }^{2}$ Shahrulazua Ahmad, ${ }^{3}$ Mohd Imran Yusof ${ }^{2}$ University Pendidikan Sultan Idris, Malaysia; '2University Sains Malaysia, Malaysia; ${ }^{3}$ University Kebangsaan Malaysia, Malaysia

\subsection{6/bjsm.2010.078725.47}

The purpose of the present study was to investigate if 12 weeks of isokinetic resistance training programme at two different angular velocities (120 and 240\%) would improve functional abilities of patients with grade III anterior cruciate ligament (ACL) injury without reconstruction. 19 subjects were recruited to the study. They were randomly assigned into three groups: control (6 subjects), $120 \%$ intervention group (6 subjects) and $240 \%$ intervention group ( 7 subjects). The first invention group $(120 \%$ s trained group) aged $36.8 \pm 7.9$ years participated in the prescribed training along with the existing conventional physiotherapy treatment. The second intervention group $(240 \% \mathrm{~s}$ trained group) aged $33 \pm 11.4$ years also participated in the prescribed training along with the existing conventional physiotherapy treatment. The control group aged $33.5 \pm 6.8$ years continued with the conventional physiotherapy only. The physiotherapy treatment was carried out by the subjects two times per week. The subjects in both the intervention groups were required to perform the isokinetic resistance training two times per week after the physiotherapy sessions. The results show that there was significant improvement $(p<0.05)$ of physical function in both intervention groups and the control group at post-training (after 12 weeks). However, there were no significant differences between the control group and intervention groups. These data indicate that isokinetic resistance training improved physical functions of patients with grade III ACL injury. Nevertheless, the existing physiotherapy programme also elicited similar benefits to these patients. Therefore, it is concluded that isokinetic resistance training combined with existing conventional physiotherapy and physiotherapy treatment alone are beneficial as a rehabilitation programme for patients with knee grade III ACL injury. 